\title{
Layanan Perlindungan Perempuan Korban Kekerasan di Women's Crisis Center Nurani Perempuan Kota Padang
}

\author{
Lusi Susanti, Fatmariza \\ Program Studi Pendidikan Pancasila dan Kewarganegaraan \\ Universitas Negeri Padang \\ E-mail: sriletari8796@yahoo.co.id
}

\begin{abstract}
ABSTRAK
Penelitian ini bertujuan untuk mendeskripsikan Program Women's Crisis Center Nurani Perempuan dalam perlindungan perempuan korban kekerasan, mendeskripsikan proses layanan terhadap korban yang dilakukan oleh Women's Crisis Center Nurani Perempuan di kota Padang, dan mengidentifikasi kendala yang dialami dalam memberikan perlindungan hak-hak perempuan korban kekerasan. Lokasi penelitian ini adalah lembaga Women's Crisis Center Nurani Perempuan. Metode yang digunakan adalah kualitatif dengan pendekatan studi kasus, dengan teknik observasi, wawancara, dan dokumentasi. Hasil penelitian ini menunjukkan bahwa program perlindungan yang dilakukan Women's Crisis Center Nurani Perempuan ada tiga yaitu pertama, kegiatan pencegahan yaitu dengan membentuk tujuh komunitas dampingan di beberapa kecamatan Kota Padang, dan melakukan sosialisasi serta diskusi dengan mahasiswa ataupun masyarakat. Kedua, program penanganan yaitu memberikan layanan berupa layanan konsultasi (psikologis dan hukum), medis, pendampingan, rumah aman (shelter), dan pemulanganan korban. Ketiga, program advokasi yaitu mengontrol kerja legislatif agar bekerja sesuai dengan tugasnya, serta mendorong pemerintah untuk membuat kebijakan yang memihak kepada perempuan korban. Kendala yang dihadapi dapat dilihat dari sumber daya manusia, sumber dana, belum adanya Memorandum of Understanding dengan lembaga lain terkait, masyarakat sekitar kurang tersosialisasi oleh Nurani Perempuan. Selanjutnya, proses layanan terhadap korban dimulai dengan dilakukan asessessment awal untuk mengetahui kebutuhan korban, korban akan diberi penguatan, mendapatkan konseling, pendampingan, dan pemulihan korban dan keluarga.
\end{abstract}

Kata Kunci: Perlindungan, Hak Perempuan, Kekerasan Terhadap Perempuan, Women's Crisis Center Nurani Perempuan.

\section{ABSTRACT}

This study aimed to describe Program Women's Crisis Center Nurani Perempuan in the protection of women victims of violence, describe the process of services for victims conducted by the Women's Crisis Center Nurani Perempuan in the city of Padang, and identify constraints experienced in the protection of the rights of women victims of violence. The location of this research is an institution of the Women's Crisis Center Nurani Perempuan. The method used is a qualitative case study approach, by observation, interviews, and documentation. The results of this study indicate that the protection program conducted the Women's Crisis Center Nurani Perempuan threefirstly, namely prevention activities by 
establishing seven assisted communities in several districts of Padang, and socializing as well as discussions with the students or the public. Second, the program handling which provides services such as consulting services (psychological and legal), medical, counseling, safe house (shelter), and repatriation of victims. Thirdly, an advocacy program that controls the work of the legislature to work in accordance with their duties, and to encourage governments to make policies that favor to women victims. Obstacles encountered can be seen from the human resources, financial resources, lack of Memorandum of Understanding with other relevant agencies, local communities are less socialized by Nurani Perempuan. Further, the process begins with a service for victims do asessessment early to know the needs of the victim, the victim will be given reinforcement, counseling, assistance, and recovery of victims and their families.

Keywords: Protection, Violence Against Women, The Women's Crisis Center

This work is licensed under the Creative Commons Attribution-ShareAlike 4.0 International License. (C2019 by author and Universitas Negeri Padang.

\section{PENDAHULUAN}

Kekerasan terhadap perempuan merupakan fenomena sosial yang sering terjadi di Indonesia dan tergolong kepada tindakan yang melanggar hak asasi manusia. Menurut data Lembar Catatan Tahunan (CATAHU) Komnas Perempuan tahun 2018, menyebutkan kekerasan terhadap perempuan yaitu kekerasan diranah rumah tangga/relasi personal meliputi kekerasan terhadap istri berada pada peringkat pertama yaitu 5.114 kasus, kekerasan dalam pacaran berada pada peringkat kedua yaitu 2.073 kasus, kekerasan terhadap anak perempuan 1.417 kasus. Kekerasan di ranah privat/personal persentase tertinggi adalah kekerasan fisik 41\% (3.951 kasus), diikuti dengan kekerasan seksual 31\% (2.988 kasus), kekerasan psikis $17 \%$ (1.638 kasus), dan kekerasan ekonomi 11\% (1.060) kasus (Komnas Perempuan, 2018).

Kekerasan terhadap perempuan sering dipandang sebagai fenomena sosial sudah biasa terjadi, bukan menjadi masalah yang serius karena korban adalah perempuan yang memang dianggap lemah. Anggapan ini diperkuat oleh adanya bias gender yang masih berkembang didalam masyarakat. Bias gender adalah pandangan yang membedakan peran, kedudukan, dan tanggung jawab antara laki-laki dan perempuan dalam kehidupan keluarga, masyarakat bahkan negara. Kasus kekerasan terhadap perempuan akan membawa dampak fisik maupun psikis yang akan dialami oleh si korban.

Tindakan kekerasan terhadap perempuan adalah termasuk kedalam tindakan yang melanggar hak asasi manusia. Akmal (2011) mengatakan bahwa pelanggaran terhadap hak asasi manusia terus berlangsung baik yang dilakukan oleh Negara maupun perorangan dan kelompok. Tindakan pelanggaran yang dimaksud adalah setiap perbuatan seseorang atau kelompok termasuk a parat negara baik disengaja ataupun tidak sengaja atau karena kelalaian yang secara melawan hukum mengurangi, menghalangi, 
membatasi, dan mencabut hak asasi maanusia seseorang atau kelompok yang dijamin oleh Undang-Undang ini (UU No. 39 tahun 1999), dan tidak mendapat atau dikhawatirkan tidak akan memperoleh penyelesaian hukum yang adil dan benar berdasarkan mekanisme hukum yang berlangsung. Karena termasuk kedalam tindakan pelanggaran HAM, maka Perempuan korban kekerasan harus mendapatkan perlindungan dan penanganan agar dapat memperoleh hak-haknya kembali. Perlindungan dapat diberikan oleh Negara maupun lembaga pengada layanan terkait.

Penelitian terkait dengan kekerasan terhadap perempuan telah dilakukan oleh beberapa peneliti. Peneliti tersebut diantaranya Zakiyah (2013) kekerasan terhadap perempuan terjadi dikarenakan dalam masyarakat masih adanya relasi gender yang timpang sehingga menimbulkan perbedaan peran dan tanggungjawab antara laki-laki dengan perempuan. Hal tersebut sejalan dengan penelitian Nasri (2016) yang menyatakan ketimpangan relasi gender juga akan menyebabkan munculnya ketidakadilan gender yang dialami perempuan. Sama halnya dengan hasil Rochaety (2014) menyatakan bahwa kekerasan terhadap perempuan baik yang terjadi di rumah, tempat kerja, dan masyarakat pada umumnya merupakan manifestasi dari ketimpangan posisi tawar dalam hubungan laki-laki dan perempuan. Realitas didalam masyarakat menunjukkan bahwa dibidang hukum, baik masalah kekerasan terhadap perempuan maupun perlindungan terhadap perempuan korban kekerasan masih belum memadai.
Perempuan yang menjadi korban kekerasan harus mendapatkan perlindungan atas hak-haknya. Menurut Sumirat (2006) perlindungan adalah upaya dalam pemenuhan hak dan pemberian bantuan untuk memberikan rasa aman kepada saksi dan/atau korban yang wajib dilaksanakan oleh lembaga perlindungan saksi dan korban atau lembaga lainnya. Hal ini diperjelas oleh Kasmawati (2017) bahwa perlindungan hak-hak perempuan dapat dilakukan dengan cara memperhatikan: a) prinsip persamaan antara laki-laki dan perempuan menuju persamaan yang subtantif, b) prinsip non diskriminasi, c) prinsip kewajiban negara menurut Konvensi. Pemenuhan atas hak-hak perempuan korban kekerasan menurut Prantiasih, dkk (2015) meliputi: a) hak untuk mendapatkan perlindungan dari Komisi Perlindungan Perempuan dan Anak (KPPA), b) hak untuk mendapatkan informasi tentang adanya tempat pengaduan untuk korban kekerasan terhadap perempuan, c) hak untuk mendapatkan jaminan atas hakhaknya sebagai istri, sebagai ibu atau anak, dalam hal ini adalah kasus kekerasan dalam rumah tangga, d) hak untuk mendapatkan pendampingan secara psikologis, medis, dan hukum, dan e) korban mendapatkan penanganan secara berkelanjutan sampai dengan tahap rehabilitasi.

Penelitian terdahulu terhadap Women's Crisis Center Nurani Perempuan adalah dalam hal Komunikasi Interpersonal Konselor Terhadap Korban Kekerasan dalam Rumah Tangga (KDRT) di Kota Padang. Penelitian tersebut memusatkan perhatian bagaimana 
proses komunikasi interpesonal konselor yang dilakukan oleh Women's Crisis Center Nurani Perempuan terhadap korban kekerasan dalam rumah tangga dan membangun kembali konsep diri bagi korban kekerasan. Berbeda halnya dengan penelitian yang akan dilakukan oleh penulis yaitu memusatkan penelitian pada upaya yang dilakukan oleh Women's Crisis Center Nurani Perempuan dalam perlindungan hakhak perempuan korban kekerasan di kota Padang.

Berdasarkan wawancara yang dilakukan peneliti terhadap lembaga Women's Crisis Center Nurani Perempuan di Kota Padang, terdapat beberapa identifikasi masalah pada saat memberikan perlindungan terhadap perempuan korban kekerasan. Masalah yang ditemukan adalah a) masyarakat masih menganggap bahwa kasus kekerasan terhadap perempuan adalah hal tabu atau aib, sehingga tidak perlu dilaporkan, b) sebagian masyarakat belum memahami bahwa kasus kekerasan terhadap perempuan adalah hal yang penting dan harus ditangani, dan c) proses penanganan hukum terhadap perempuan yang mengalami kekerasan berjalan lambat oleh pihak kepolisian.

Berdasarkan permasalahan diatas, menurut informan hal yang sudah dilakukan oleh Nurani Perempuan adalah sudah melakukan sosialisasi kepada masyarakat di kota Padang melalui dibentuknya komunitas ibu-ibu di beberapa kecamatan yang diberi edukasi tentang hal-hal yang berkaitan dengan perempuan dan anak. Sehingga komunitas tersebut bisa melakukan sosialisasi dengan masyarakat di wilayahnya. Nurani perempuan juga melakukan penanganan dengan melakukan berbagai layanan untuk mengangani korban. Namun, informan juga mengaku masih mengalami kesulitan karena berbagai hal salah satunya kurangnya sumber daya manusia/pengurus untuk menangani kasus yang masuk, serta kurang sumber dana untuk penanganannya.

Peniliti memberikan saran untuk keterbatasan solusi yang ada, yaitu diharapkan kedepannya dapat menambah jumlah sumber daya manusia atau pengurus organisasi, dan ditempat dimasing-masing divisi yang sudah terlatih. Tujuannya agar setiap program dan penangangan dapat dijalankan dengan maksimal. Serta diharapkan pemerintah dapat memberikan anggaran dana kepada lembaga pengada layanan terkait untuk menganani perempuan korban kekerasan.

Tujuan dari penelitian ini adalah untuk mendeskripsikan bagaimana upaya perlindungan hak-hak perempuan korban kekerasan yang ditangani oleh Women's Crisis Center Nurani Perempuan di Kota Padang. Apabila penelitian ini dilakukan harapan penulis adalah kedepannya masyarakat mendapatkan informasi bahwa sudah terdapat lembaga yang menganani dan memberikan perlindungan kepada

\section{METODE PENELITIAN}

Penelitian ini menggunakan metode penelitian kualitatif. Melalui pendekatan kualitatif dengan metode wawancara, observasi, dan dokumentasi diharapkan data dapat diperoleh dengan baik. Lokasi penelitian ini adalah lembaga 
Women's Crisis Center Nurani Perempuan di kota Padang. Lokasi ini dipilih untuk dijadikan tempat penelitian adalah karena lembaga ini memfokuskan pada isu perempuan, yang ditengah kehidupan masyarakat sekarang banyak ditemukannya diskriminasi terhadap perempuan dalam berbagai aspek kehidupan. Adapun informan dalam penelitian ini adalah 1) tiga orang Pengelola atau pengurus, 2) Relawan, 3) dua orang korban, 4) masyarakat lingkungan Nurani Perempuan, 5) Dinas Pemberdayaan Perempuan, Perlindungan Anak, Pengendalian Penduduk dan Keluarga Berencana (DP3AP2KB) Padang, 6) Dinas Sosial Padang, 7) Polresta Padang. Teknik pengumpulan data pada penelitian ini dilakukan dengan cara wawacara, observasi, dan dokumentasi. Terknik analisis data dimulai dari pengumpulan data, reduksi data, penyajian data, dan menarik kesimpulan atau verifikasi.

\section{HASIL DAN PEMBAHASAN}

Perlindungan perempuan dan anak adalah upaya dalam pemenuhan hak dan pemberian bantuan untuk memberikan rasa aman kepada perempuan dan anak. Perlindungan dapat diberikan kepada korban dalam arti sebagai perlindungan hukum untuk tidak menjadi korban tindak pidana (Rajaguguk, 2014). Kemudian perlindungan untuk memperoleh santunan/jaminan hukum atas penderitaan atau kerugian orang yang telah menjadi korban tindak pidana.

Bentuk-bentuk perlindungan tidak hanya berupa Undang-Undang yang dibuat oleh lembaga legislatif sebagai bentuk perlindungan dari Negara. Tetapi dapat diberikan oleh pihak mana saja misalnya Komisi
Nasional HAM, Komnas Anti Kekerasan Terhadap Perempuan, Lembaga Bantuan Hukum Asosiasi Perempuan Indonesia untuk Keadilan (APIK), dan salah satunya Lembaga Women's Crisis Center Nurani Perempuan.

Berdasarkan temuan peneliti dilapangan proses layanan korban yang ditangani oleh Nurani Perempuan dapat dikatakan sudah baik. Dapat dilihat bahwa pelayanan yang diberikan dimulai dari assessment awal untuk menentukan apa saja yang menjadi kebutuhan korban. selanjutnya korban akan mendapatkan beberapa layanan yang tersedia, seperti pendampingan psikologis, hukum, rumah aman, sampai dengan pemulihan korban. Sejauh ini Nurani Perempuan selalu mengupayakan memberikan layanan maksimal untuk korban dan memenuhi kebutuhan korban sesuai dengan kasus yang dialami.

Women's Crisis Center Nurani Perempuan mempunyai program salah satunya adalah program pencegahan melalui sosialisasi. Berdasarkan hasil temuan peneliti sosialisasi Nurani Perempuan sudah terjalankan dengan baik. Hal ini dapat dilihat dari adanya kegiatan sosialisasi yang dijalankan bersama dengan komunitas. Selain itu, sosialisasi juga dilakukan dalam bentuk penyebaran pamflet ke masyarakat untuk memberikan informasi tentang kekerasan terhadap perempuan. Yang mana materi yang disampaikan merupakan suatu kebutuhan yang memang penting untuk diketahui dan dipahami masyarakat. Sebagaimana menurut Susanto (1992) mengatakan bahwa materi sosisalisasi harus mengandung peran yang berupa pengetahuan. 
Dengan pengetahuan itu dapat digunakan untuk mendukung suatu nilai khusus atau suatu sikap. Sehingga dengan pengetahuan yang dimiliki masyarakat dapat menentukan sikap.

Berdasarkan hasil penelitian Mahardika (2012) menyatakan Lembaga Swadaya Masyarakat berperan dalam membangun kemandirian dalam masyarakat, terkhusus kemandirian bagi perempuan yang menjadi korban tindak pidana kesusilaan. Proses dalam membantu membangun kemandirian bagi perempuan yang menjadi korban dimulai dengan pendampingan, memberikan konseling yang membuat si korban merasa nyaman dan aman saat ditangani. Sama halnya dengan Nurani Perempuan yang memberikan pelayanan agar korban dapat mandiri dan berdaya. Namun, Proses perlindungan yang dilakukan oleh Nurani Perempuan dalam pelaksanaannya masih menemukan beberapa kendala. Diantaranya kurangnya jumlah tim yang melakukan sosialisasi, karena untuk mencapai tujuan maksimal agen sosialisasi tidak hanya dilakukan oleh satu orang saja. Selanjutnya dalam setiap proses penanganan korban juga membutuhkan biaya seperti korban yang harus di visum dan biaya korban tidak ditanggung oleh negara. Hal ini sama dengan masalah yang sering ditemui dalam LSM adalah sistem perekrutan staf yang tidak jelas, tidak adanya sistem pembagian kerja yang nyata, keberlangsungan program yang rendah, ketidakpastian sistem pendanaan, dan lain sebagainya.

Perlindungan hak-hak korban diatur dalam norma atau aturan yang mengandung nilai-nilai luhur yang menjunjung tinggi martabat manusia dan menjamin HAM. Oleh karena itu juga tercermin dalam beberapa kebijakan regulasi atau UndangUndang yang memberikan perlindungan kepada perempuan dan anak (Sumirat, 2016). Hukum pada dasarnya merupakan cerminan yang mengandung keadilan dan memcerminkan perlindungan kepada setiap warga negaranya. Sebagaimana halnya dengan Nurani Perempuan berusaha untuk mendorong pemerintah terutama lembaga legislatif agar membuat kebijakan yang melindungi perempuan dan anak yang menjadi korban. sehingga regulasi yang dibuat akan memihak kepada korban. Upaya advokasi yang dilakukan dengan cara melakukan audiensi dengan pemerintah, melakukan aksi damai, kampanye untuk memperingati hari-hari tertentu seperti Hari Perempuan Iinternasional dan lain sebagainya.

\section{KESIMPULAN}

Hasil dari penetian ini menyatakan bahwa Lembaga Women's Crisis Center (WCC) Nurani Perempuan dalam membela hak-hak perempuan korban kekerasan adalah dengan melakukan program kegiatan yaitu kegiatan pencegahan, kegiatan penanganan, dan advokasi atau mendorong lahirnya kebijakan. Kendala yang sering dihadapi adalah kurangnya sumber daya manusia yang bertugas untuk melakukan sosialisasi dan pendampingan kasus. Selain itu, belum adanya anggaran dana pemerintah untuk korban. Nurani Perempuan selalu mengupayakan pelayanan yang maksimal bagi para korbannya. Proses pelayanan bagi 
korban yang masuk akan dimulai dari kegiatan assessment awal yang bertujuan untuk mengetahui apa saja yang menjadi kebutuhan korban. Setelah itu, korban akan mendapatkan penguatan kemudian pendampingan baik itu berupa psikologis, medis, dan hukum serta rumah aman. Setelah kasus selesai, korban juga akan menerima layanan pemulihan agar korban bisa berdaya dan dapat menentukan sikapnya sendiri.

Penelitian ini akan memberikan kontribusi terhadap bidang ilmu sosial terutama pada mata kuliah yang berbasis gender. Kekerasan berbasis gender sangat banyak terjadi pada saat ini. Oleh sebab itu, masyarakat terutama perempuan yang mengetahui maupun mengalami kekerasan dapat melaporkan kepada pihak yang menangani kasus tersebut, salah satunya adalah lembaga Women's Crisis Center Nurani Perempuan di Kota Padang. Lembaga ini mengupayakan adanya perlindungan dan penanganan kepada perempuan yang menjadi korban kekerasan.

\section{DAFTAR PUSTAKA}

Akmal. (2011). Hak Asasi Manusia (Teori dan Praktik). Padang: UNP Press.

Kasmawati, Andi. (2017). Perlindungan hak perempuan dalam perspektif keadilan gender. Universitas Negeri Malang.

Perempuan, K. (2018). Lembar Fakta Catatan Tahunan (CATAHU) Komnas Perempuan Tahun 2018: Kekerasan Terhadap Perempuan: Negara Segera Putus Impunitas Pelaku. Jakarta: Komnas Perempuan.

Mahardika, Friska. (2012). "Peran Lembaga Swadaya Masyarakat
(LSM) dalam Perlindungan Perempuan Korban Tindak Pidana Kesusilaan di Puwokerto". Unuversitas jenderal soedirman. Skripsi.

Nasri, D. (2016). Ketidakadilan Gender Terhadap Perempuan dalam Novel Padusi Karya Ka'bati.

Prantiasih, A, dkk. (2015). Model Perlindungan Hak Perempuan Korban Tindak Kekerasan dalam Rumah Tangga. Semarang: Jurnal Pendidikan Pancasila dan Kewraganegaraan. No. 1.

Rochaety, Nur. (2014). Menegakkan HAM Melalui Perlindungan Hukum Bagi Perempuan Korban Kekerasan di Indonesia. Jurnal Palastren vol.7 no. 1.

Rajagukguk, D. (2014). "Peranan Lembaga Swadaya Masyarakat Cahaya Perempuan Women's Crisis Center (WCC) Dalam Memberi Perlindungan Pada Korban Kekerasan Dalam Berpacaran Di Kota Bengkulu". Universitas Bengkulu. Skripsi.

Sumirat, Iin Ratna. (2006). Perlindungan Hukum Terhadap Perempuan dan Anak Korban Kejahatan Kejahatan Perdagangan Manusia. Jurnal Studi Gender dan Anak. Vol.3 No. 1.

Susanto, (1992). Sosialisasi Pelayanan. Malang: Universitas Kanjuruan. Undang-undang Nomor 39 Tahun 1999 Tentang Hak Asasi Manusia

Zakiyah, Siti. (2013). Kekerasan Gender Berbasis Gender dan Teks-Teks Relasi Gender dalam Islam. Jurnal Muzawah. vol. 5 no.2. 